Blended pastes of cement and lime: pore structure and capillary porosity

M. Arandigoyen, J.I. Alvarez *

Departamento de Química, University of Navarra, 31080 Pamplona, Spain

$\mathbf{N}^{\circ}$ of pages: 35

$\mathbf{N}^{0}$ of tables: 3

$\mathbf{N}^{0}$ of figures: 12

PACS Codes: $81.05 . \mathrm{Rm} \quad$ 68.35.Fx

Keywords: Microstructure, surface fractal dimension, capillary absorption, blended pastes

Please, send all correspondence to:

Dr. José I. Alvarez Galindo

Dpto. de Química

Fac. de Ciencias

Universidad de Navarra

$\mathrm{C} /$ Irunlarrea $\mathrm{s} / \mathrm{n}$

31.080 Pamplona (Navarra)

Spain

Phone: 34948425600

Fax: 34948425649

E-mail: jalvarez@unav.es 


\title{
Blended pastes of cement and lime: pore structure and capillary
}

\section{porosity}

\begin{abstract}
Microstructure of blended pastes of lime and cement were studied in this paper. An increment of complexity of the microstructure was found when pastes increase their percentage in cement. Microstructural characteristics as porosity, morphology of the pores, pore size distribution and surface fractal dimension were evaluated in the different pastes studying the modification with the variation of composition. The capillary water absorption is also evaluated obtaining higher capillary coefficients values for the pastes with higher amounts of lime. The increase of complexity of the microstructure, due to the cement in the pastes, leads to slight deviations of the parallel tube model.
\end{abstract}

Keywords: Microstructure, surface fractal dimension, capillary absorption, blended pastes

PACS Codes: 81.05.Rm 68.35.Fx 


\section{Introduction}

In a previous work by the research group, pore structure and capillary porosity were studied in lime pastes with different kneading water [1]. The framework of the research is to describe binding materials in order to be used in restoration works of cultural heritage.

Firstly, the bad compatibility of Portland cement with some aspects of restorations requirements, such as the aggression to the stones due to the high amount of salts, the low flexibility, and the scarce compatibility with old materials have been reported [2]. On the other hand, the slow settings of lime mortars, as well as their low mechanical strengths have also been discussed. This situation leads to the study of blended binding materials, which could share in the advantages of lime and cement mortars, avoiding or reducing their disadvantages. These blended materials will be characterized by faster setting than lime and better compatibility with the old materials and the stone than cement mortars.

One important side of the knowledge of these blended mortars is the study of the microstructure and related properties, which gives information about: i) the future degradation of the material [3,4]; ii) transport and accumulation of water [5]; iii) kind of diffusion of gases through the material [6], and, related with this, the kinetic of some reactions that can take place [7].

One of these microstructural properties, the capillary porosity, is a consequence of the porous nature of building materials and their exposure to the environmental conditions. This capillary porosity is closely related to the moisture transport. Actually the capillary transport is the main driving mechanism for the chloride and the sulphate ions, and absorbed water by capillarity can be a problem as a consequence of the 
freezing/thawing phenomena. Therefore, this capillary porosity as well as the pore structure of the binding materials are linked with durability, degradation and service life of the building materials $[8,9]$. In a previous paper, theory on capillary water absorption was given [1].

Fractal geometry as a reflection of the complexity of the porous system has been widely studied in this kind of materials to obtain the surface fractal dimension $\left(D_{S}\right)$. Several works discuss the changes in $\mathrm{D}_{\mathrm{S}}$ as a function of different $\mathrm{W} / \mathrm{B}$ ratio in limes [1], W/B in surface fractures of cements [10] or composition of the binding materials [11]. Data from mercury intrusion porosimetry have been used to obtain the pore surface fractal dimension.

Given that the paste is the main factor of porosity in a binding material [4], in this paper the study focuses on blended pastes. The purpose of this paper is to evaluate the pore structure in different blended pastes, regarding their composition, using the fractal geometry, and also the capillary sorption as a relevant hygrometric property.

\section{Experimental work}

\subsection{Pastes preparation}

A hydrated commercial lime powder $\left(\right.$ Ecobat $\left.^{\circledR}\right)$ (supplied by Calinsa S.A, Navarra, of the class CL90 according to Spanish standard [12]) and a Portland cement CEM II-A/L 32.5 (according to the Spanish standard [13]) was used. Chemical and mineralogical composition of this aerial lime and this cement is discussed in section 3.1 below.

60 cylindrical specimens of $4 \mathrm{~cm}$ (diameter of $3.4 \mathrm{~cm}$ ) were elaborated blending the lime with the cement in order to obtain six different compositions (\%lime) $(100,80,60$, 
40, 20 and $0 \%$ of lime) (Table 1), with 10 specimens of each composition. Different amounts of kneading water were employed in order to obtain a similar consistency in all the pastes. The amount of kneading water employed increases with the content in lime, thus, also the $\mathrm{W} / \mathrm{B}$ ratio increases.

The pastes were blended for 5 minutes in a Proeti ETI 26.0072 mixer, molded in the cylindrical casts and demolded 3 days later. The specimens were cured in a vertical position in ambient laboratory conditions (RH $60 \pm 10 \%$ and $20 \pm 5^{\circ} \mathrm{C}$ ) for 2 years. The surrounding $\mathrm{CO}_{2}$ in the room was estimated to be the standard atmospheric concentration $(0.033 \pm 0.001 \%(\mathrm{v} / \mathrm{v}))$.

In order to evaluate the properties of the pastes, the specimens were dried at $90^{\circ} \mathrm{C}$ by progressive heating with the purpose to minimize damages because of cracking in the material. Thus, the free water was totally removed from all the specimens.

All reported analytical results are the average value of the three identical specimens tested.

\subsection{Analytical methodology}

\subsubsection{XRD analysis}

The mineralogical phases present in the specimens were determined by means of X-ray diffraction (XRD) using a Brucker D8 Advance diffractometer, according to the diffraction powder method, with a $\mathrm{CuK}_{\alpha 1}$ radiation and $0.022 \theta$ increment and $1 \mathrm{~s} \cdot \mathrm{step}^{-1}$, sweep from 10 to $80^{\circ} 2 \theta$. The results were compared with the ICDD (International Center for Diffraction Data) database. 


\subsubsection{SEM, BSE and EDAX analyses}

Scanning Electron Microscopy (SEM), Backscatter Scanning Electron (BSE) and Electron Dispersion Analysis of X-ray (EDS) in a Digital Scanning Microscope DSM940 A Zeiss was used for microscopic observation of the morphology of the microstructure, and for local composition.

\subsubsection{Pore structure}

The pore structure was evaluated in two ways:

2.2.3.1. Open porosity measurement: the total porosity is expressed as $\mathrm{P}$, in percent, and is determined according to the water saturation test [14] with a hydrostatics balance.

2.2.3.2. Pore size distribution is evaluated using the mercury intrusion porosimetry technique with a Micrometrics 9320 Poresizer mercury porosimeter, with automatically registers pressure, pore diameter, intrusion volume and pore surface area.

\subsubsection{Capillary absorption}

The capillary water absorption was measured with the assembly presented in Fig. 1. The specimen is held by the balance. Water only contacts the specimen at the bottom face. At this moment, the electronic timekeeping starts and the water is absorbed in the specimen by capillary action. The weight increment due to the absorbed water is registered by the computer. The change of the water level can be assumed as negligible due to the small amount of the water absorbed by the specimen during the test because 
the small size of the specimen,. Test was carried out during several hours, with the aim to achieve a complete saturation of the specimen.

\section{Results and discussion}

\subsection{Mineralogical and chemical composition of the pastes}

Table 2 presents the chemical analysis and standard deviation of the lime and the cement used.

Chemical analysis shows a lime with a high degree of purity (CL 90): low content of $\mathrm{SiO}_{2}$ and $\mathrm{MgO}$, as well as small amounts of soluble salts (expressed as $\mathrm{Na}_{2} \mathrm{O}$ and $\mathrm{K}_{2} \mathrm{O}$ ). In the cement the $\mathrm{MgO}$ amount is within the specifications, $(<5 \%)$.

XRD analyses were performed in order to study the mineralogical composition of the lime and the cement. X-ray diffraction results show (Fig. 2) that only two mineralogical phases are present in the lime: portlandite $\left(\mathrm{Ca}(\mathrm{OH})_{2}\right)$ (ICDD 44-1481) as the main phase, and calcite $\left(\mathrm{CaCO}_{3}\right)$ (ICDD 05-0586), as a result of a slight carbonation [2]. No diffraction peaks of magnesium compounds $\left(\mathrm{MgO}, \mathrm{Mg}(\mathrm{OH})_{2}\right.$, dolomite or magnesite) were identified. Termogravimetic analysis carried out in a previous paper [1] had shown $87 \%$ of $\mathrm{Ca}(\mathrm{OH})_{2}, 10 \%$ of $\mathrm{CaCO}_{3}$ and $3 \%$ of humidity.

XRD analysis of the cement shows the typical phases of the clinker: belite -dicalcium silicate- $\left(\mathrm{Ca}_{2} \mathrm{SiO}_{4}\right)$ (ICDD 01-1029), alite -tricalcium silicate- $\left(\mathrm{Ca}_{3} \mathrm{SiO}_{5}\right)$ (ICDD 011024), calcium aluminate $\left(\mathrm{Ca}_{3} \mathrm{Al}_{2} \mathrm{O}_{6}\right)$ (ICDD 38-1429), aluminoferrite (4CaO. $\left.\mathrm{Al}_{2} \mathrm{O}_{3} \cdot \mathrm{Fe}_{2} \mathrm{O}_{3}\right)$ (ICDD 85-1092). Calcite (ICDD 05-0586) and calcium sulphate hydrate (gypsum) (ICDD 01-0385) are also present in the cement as regulators of the setting (Fig. 3). 
Fig. 4 shows the XRD analyses carried out at two curing years in order to evaluate the chemical and mineralogical compositions. The XRD results show that only the lime paste is totally carbonated because the portlandite peak appears in the other pastes. Only the peaks of the calcite, portlandite and unhydrated calcium silicates are detected because the hydrated products have a gel non-crystalline structure and they can not be detected by this technique. The cement in all the blended pastes reaches a high degree of hydration because either the diffraction peaks of unhydrated calcium silicates are missing or they are dimmed: for example, the pure cement paste shows a diffraction peak of belite that indicates that the hydration is not completed. Also in the $20 \%$ lime specimens a small peak can be detected. It is possible to say that the hydration takes place in a more complete way in pastes with higher lime amounts than in pastes with higher cement amounts. This fact can be due to the higher amount of kneading water required by pastes rich in lime.

\subsection{SEM, BSE and EDAX observations}

Fig. 5 shows the SEM images of a lime paste (a), and a blended paste (b) with $40 \%$ lime and $60 \%$ cement. As image (a) shows, the microstructure is an aggregate of crystals of calcite as explained in a previous research [1], influenced by the crystal size [15] and by the $\mathrm{W} / \mathrm{B}$ ratio, and with a good homogeneity. In image (b), the amorphous structure of the gel [16] formed in the hydration of the calcium silicate of the cement, creates an irregular morphology (centre of the image). In this case, the crystals of calcite mixed with the gel structure can also be seen (calcite crystals are shown in circles in Fig. 5, b). Furthermore, the morphology of hydrated calcium silicates can adopt a great variety of irregular shapes [17] as a function of the curing conditions and the cement composition. 
A clear difference in morphology between the lime pastes and the hydrated calcium silicates has been established. Therefore, the blended pastes have a combination of both morphologies, which will be a function of the proportion between lime and cement.

Fig. 6 shows the BSE images of the four blended pastes after two curing years. The image (a) shows the BSE of the $20 \%$ blended paste. It is a very heterogeneous image in which areas of different colour are found (as a function of its composition). The white areas are the unreacted calcium silicates (1). In some of the areas the hydration rim of C-S-H described by S. Diamond [18] can be seen (indicated by the number 2, with a black circle in picture a), which indicate that the cement grains are partially hydrated. The grey areas (2) are the fully hydrated calcium silicates, with less brightness due to the smaller atomic number of the water in comparison with the calcium silicates. The areas with a discontinuous black-grey (3) are the lime zones which are characteristic because their high porosity. The black points and areas are the pores (4) [18]. In the $40 \%$ lime (picture b), the white areas do not appear and only grey areas are present included in a matrix of lime. These BSE results are in concordance with the XRD at two years. This fact can be understood because a more complete hydration takes place. The percentage of discontinuous black-grey areas (3) increases, due to a higher percentage of lime in the paste. In the $60 \%$ lime paste (picture c), the amount of hydrated silicates (2) decreases and disappears almost completely in the $80 \%$ lime (picture d). In the $60 \%$ and $80 \%$ lime, the composition seems to be quite homogeneous except for some areas that present higher porosities and can be identified by their darker colour. In Fig. 7, corresponding to an image of a $60 \%$ lime paste with a larger magnification, it can see a dense particle of hydrated calcium silicate (determined by EDS) can be seen surrounded by an aggregate of small crystals, principally lime. The amount of these dense particles 
decreases with the increase of the percentage in lime, resulting in materials with a more homogeneous porosity.

Therefore, a large difference between the two extremes of the blended pastes can be appreciated (Fig. 6 a) and d)). While the $20 \%$ lime paste is quite heterogeneous with dense particles (unreacted calcium silicate), the $80 \%$ lime paste is quite homogeneous with some areas with a higher porosity. Thus, it can be established a regular variation between the two extremes along the series.

\subsection{Pore structure}

\subsubsection{Open Porosity}

Fig. 8 shows the experimental results of the porosities obtained by two techniques: MIP, and absorption of water by immersion. Porosity varies with the composition of the paste in a wide range, decreasing when the percentage of cement increases. This variation can be attributed to: i) the amount of kneading water employed in the elaboration of the pastes (in order to get a similar consistency for all the pastes) that decreases with the percentage of cement in the paste, as shows Table 1; ii) the swelling of the structure produced as a consequence of the hydration of the calcium silicates that diminishes the porosity. Therefore, porosity for pure lime pastes varies between 50 and $65 \%$ in function of the W/B ratio [1], while for pure cement pastes, porosity is practically half (as can be seen in Fig. 8, samples 0\% lime).

In a previous study, the microstructure of lime pastes was reported [1]: porosities obtained by MIP were higher by $2 \%$ than the ones obtained by the absorption of water by immersion technique. However, in the case of blended pastes (Fig. 8), the porosities 
are higher with the water absorption technique. Furthermore, in blended pastes the difference between both techniques is not constant contrary to the difference in lime pastes: in blended pastes the difference increases when the content in cement increases. This difference can be due to the presence of the gel pores $(<5 \mathrm{~nm})$, characteristic of the microstructure of hydrated cement. These gel pores do not appear in lime pastes [1]. MIP technique, with a maximum pressure of 60.000 psi (related to a diameter of 0.003 $\mu \mathrm{m})$ can not introduce mercury in all the gel pores, but water can be because of its surface tension. Thus, when the amount of cement increases so does the amount of gel pores increasing the difference in porosity between both techniques. In lime pastes the difference between both techniques can be due to the dissolution of a small part of the sample during the test of absorption of water by immersion. After the test, a white thin layer is observed on the surface of the water. The dissolution of a part of the sample causes a loss of weight that is translated in less amount of water absorbed, and thus, to a less porous material.

\subsubsection{Pore size distribution}

As SEM results shown, lime and cement pastes are very different in morphology, thus, it is expected to find a great difference in the pore size distribution between both materials. A pore size distribution analysis has been carried out in a wide range, from $350 \mu \mathrm{m}$ to $0.003 \mu \mathrm{m}$ pore diameter. However, while lime pastes show porosity in a narrow range of pores $[1,2]$, blended pastes show porosity in a wider range.

Fig. 9 shows the results of the cumulative pore size distribution by MIP for the six different pastes. Each distribution is the average of three measurements, with a good accuracy. Although this technique has some disadvantages [19] (ink-bottle and that the 
pores are not exactly cylindrical and equally accessible to the mercury) is widely accepted for the study of these materials [20,21]. Anyway, the disadvantages almost disappear in lime pastes (due to their simple microstructure [1]) and increases with the percentage of cement in the paste. All the pores are smaller than $1 \mu \mathrm{m}$, and the distribution is a function of the composition of the paste. When the percentage of cement in the paste increases, the curvature of the graphics decreases, and becomes almost a straight line for the cement paste. This indicates a wider distribution of the pores (including capillary and gel pores) as a consequence of a more complex structure of the hydrated calcium silicates in comparison with the aggregate of crystals of calcium carbonate of the lime. Thus, when the amount of cement increases in the paste, new pores below $0.05 \mu \mathrm{m}$ appears, while the pores between 0.3 and $0.8 \mu \mathrm{m}$ decrease in a high degree as a consequence of the decrease of the amount of lime, responsible for this range of pores sizes.

Because the MIP does not measure the intrusion volume at equidistant pressures, it is necessary to realize a derivative of the intrusion volume respect to the diameters of pore to obtain a realistic differential pore size distribution, in order to evaluate the main pore diameter. As Fig. 10 shows, when the pastes increase their percentage in cement, the percolation diameter shifts toward smaller diameters, and the area below the peak decreases until the rate of change becomes almost a straight line for the cement paste. Therefore, in pastes rich in lime the percolation takes place at higher pore diameter [1] than in pastes increasing their percentage in cement. In $100 \%$ cement pastes, no percolation pore diameter is found. Threshold diameter has been defined as a diameter corresponding to a pressure below which very little intrusion into the specimen is recorded, and immediately above which the greatest portion of the intrusion takes place [22]. Values for threshold diameter are about $0.7 \mu \mathrm{m}$ for high cement mixes and $0.5 \mu \mathrm{m}$ 
for high lime mixes. In lime pastes the threshold diameter increases clearly with the $\mathrm{W} / \mathrm{B}$ ratio [1], however, in blended pastes with higher percentage of lime this parameter decreases with the increment of the percentage of cement.

\subsubsection{Surface fractal dimension}

In a previous work [23], pore fractal objects were defined as dense objects. In these objects exist a distribution of pores with a fractal structure. Fractal geometry is used to describe chaotic systems which are characterized by their invariability at any scale used to examine them: any part or the system looks the same as the whole (self-similarity) [24]. System is determined by fractal dimension value, which is defined as an intermediate dimension between the Euclidean dimensions (point 0, line 1, plane 2 and volume 3) as a consequence of the complexity of the system [5].

In these lime pastes the pore surface fractal dimension $\left(D_{S}\right)$ (i.e. the Koch surface) is studied, taking values between 2 (plane) and 3 (volume). This value $\left(\mathrm{D}_{\mathrm{S}}\right)$ gives a description of the heterogeneity and complexity of the system. Perez Bernal et al. [24] explain and compare several methods to calculate this parameter. In this case a model elaborated by Zhang and $\mathrm{Li}$ [25] derived from thermodynamic considerations and dimensional analysis has been applied to the mercury intrusion porosimetry data (Eq. 1), obtaining good correlation coefficients. To obtain the $D_{S}$ values the $Q_{n}$ term is plotted versus the $W_{n}$ term giving values to $D$ until the slope is the unit. Thus, the $D$ obtained is the surface fractal dimension.

$$
Q_{n}=-\sum_{i=1}^{n} \overline{P_{i}} \Delta V_{i} \quad \propto \quad r_{n}^{2-D} V_{n}^{D / 3}=W_{n}
$$


where $\mathrm{P}$ is the pressure applied, $\mathrm{V}$ the volume of intruded mercury, $\mathrm{r}$ the pore radius and $\mathrm{D}$ the surface fractal dimension. $\mathbf{Q}_{\mathbf{n}}$ is the shortened expression of

as well as $\mathbf{W}_{\mathbf{n}}$ is of

$$
-\sum_{i=1}^{n} \overline{P_{i}} \Delta V
$$

$$
r_{n}^{2-D} V_{n}^{D / 3}
$$

This model seems applicable to this kind of materials, as proved by the correlation coefficients higher than 0.99 . The study has been limited to the interval between 0.007 $\mu \mathrm{m}$ and $0.5 \mu \mathrm{m}$ (except for the 100 and $80 \%$ pastes that has been limited to 0.020 due to the narrow range of pore distribution). According to Pfeifer and Obert [26], to accept an experimental fractal dimension, the pore diameter range used to calculate the fractal dimension should expand one decade or more. This requirement has been fulfilled in the present work.

From these results (Table 3), the values of $\mathrm{D}_{\mathrm{S}}$ obtained by MIP (average of the three measurements) increase when pastes increase their percentage in cement. This behaviour can be attributed to the differences in morphology between the lime and the hydrated calcium silicates. Therefore, the complexity of the structure increases with the percentage of cement in the paste. Also, this variation of $D_{S}$ could be related to the variation in the W/B ratio: however, a previous work about lime pastes [1] shows the invariability of the $\mathrm{D}_{\mathrm{S}}$ with the $\mathrm{W} / \mathrm{B}$ ratio, at least in lime pastes. Besides, a study carried out in cement pastes with different W/B ratio about the fractal dimension of the fracture surface by a stereoscopic SEM also shows the independence of the $\mathrm{D}_{\mathrm{S}}$ with respect to the $\mathrm{W} / \mathrm{B}$ ratio [23].

Furthermore, the increment of the $\mathrm{D}_{\mathrm{S}}$ values is proportional to the percentage of cement in the paste (except for the $100 \%$ lime paste), with a correlation coefficient of 0.98 . 


\subsection{Capillary absorption}

When a capillary is in contact with a liquid, it creates a difference of pressure $\Delta \mathrm{P}$ inversely proportional to its radius, forcing the liquid to go inside the capillary, as shown in Eq.2:

$$
\Delta P=2 \gamma \cos \theta / r
$$

where $\gamma$ is the surface tension of the liquid, $\theta$ the contact angle and $r$ the radius of the capillary. The parallel tube model of porous media has been extensively reported [8], as shown in Eq. 3, which considers the material as consisting of a group of straight parallel capillaries, instead of a random porous material:

$$
M_{S}=C_{A} \cdot \sqrt{t}+C_{0}
$$

where $M_{S}$ is the mass of water absorbed with respect to surface area $\left(g / \mathrm{m}^{2}\right), C_{A}$ is the capillarity coefficient $\left(\mathrm{g} / \mathrm{cm}^{2} \cdot \mathrm{s}^{1 / 2}\right), \mathrm{t}$ is the time (s) and $\mathrm{C}_{0}$ is a value that is a function of the surface of contact with the water $\left(\mathrm{g} / \mathrm{cm}^{2}\right)$. Eq. 3 comes up as a consequence of applying the Darcy's law to a capillary tube.

Fig. 11 shows the mass of water absorbed by the specimen versus $t^{1 / 2}$ for each one of the six different pastes in order to obtain linear relationships.

As Fig. 11 shown, the capillary behaviour of blended pastes diverts from the parallel tube model when the percentage of cement in the paste increases. In the case of $100 \%$ lime paste, the capillary behaviour adjusts in a perfect way to the model, increasing the capillary coefficient with the W/B ratio [1]. For blended pastes with a percentage of 
cement between 80 and $40 \%$, the graphics divert from the model in a slight way. At the lower time, the graphics are diverting a quite bit from the model. For pastes with a percentage of cement between 20 and $0 \%$ the deviation is more important and a deflection point appears. The same behaviour can be observed in other publications about concrete [27], although the graphics are treated as straight lines by applying this model.

The deviation from the parallel tube model increases when the percentage of cement in paste increases. This fact can be explained considering the microstructure: pore size distribution and morphology. In lime pastes the existence of practically a unique pore size (that changes with the $\mathrm{W} / \mathrm{B}$ ratio) and a homogeneous, high porosity creates a structure very similar to the one described by the model. Besides this, in lime pastes there is a good connectivity between the pores. On the other hand, the MIP studies of the pastes rich in cement shown a complex pore size distribution (with a wider range of pores) with some problems for the diffusion of fluids through their structure: i) the connectivity between pores is not as good as in lime pastes, as a consequence of the gel nature of cement; ii) the heterogeneous porosity along the material with dense particles owing to the cement (Fig. 7) that have to be surrounded by the fluid in its diffusion route, travelling a longer distance than the straight line; and iii) in the rise of the water through the structure a meniscus is created (air/water interface) [8]. The contact angle of the meniscus is a function of the surface tension of the liquid and of the nature of the material. In this case while the structure gets more complex the meniscus needs to change its orientation in more often due to the random porosity. Therefore, the deviation from the model increases when the pastes increase their percentage in cement [8].

Dividing the slope of each graphic of Fig. 11 between the surface of contact of the each specimen with the water, leads to the $C_{A}$, i.e. the capillary coefficient $\left(\mathrm{g} / \mathrm{cm}^{2} \mathrm{~s}^{1 / 2}\right)$, 
according to Eq. 3. In Fig. 12, these values are represented versus the percentage of lime in the pastes.

As can be observed, capillary coefficient increases with the percentage in lime. It must be pointed out that the $\mathrm{W} / \mathrm{B}$ ratio modifies this parameter in lime materials [1] the same as in cement materials [4], increasing it due to larger pore diameters. Thus, the capillary coefficient value for each blended paste oscillates in a range of values below and above the ones given in Fig. 12 as a consequence of the W/B ratio.

\section{Conclusions}

1) The microstructure of blended pastes increases its complexity with the increment of the percentage of cement, showing a more complex pore size distribution and more amorphous morphology due to the gel nature of the hydrated calcium silicates. The porosity decreases in a high degree with the increment of cement in the paste.

2) The complexity of the surface also increases with the percentage in cement, increasing the surface fractal dimension obtained with the MIP data, from a $\mathrm{D}_{\mathrm{S}}$ of 2.381 for a pure lime paste until a $\mathrm{D}_{\mathrm{S}}$ of 2.666 for a pure cement paste.

3) The increment of complexity of the microstructure with the increase of cement in the paste is reflected in a deviation of the capillary absorption behaviour from the parallel tube model, while the capillary coefficient decreases almost in a linear way with the percentage in cement. Therefore, in order to choose a binding material for restoration works, high cement mixes would have a great durability in front of the moisture, due to their microstructure and capillary coefficient. 


\section{Acknowledgements}

The present study was supported by the Spanish Ministerio de Ciencia y Tecnología, Plan Nacional de Investigación, Desarrollo e Innovación Tecnológica (I+D+I) program, Project MAT 2000-1347.

\section{References}

[1] M. Arandigoyen, J.L. Pérez Bernal, M.A. Bello López, J.I. Alvarez, Lime pastes with different kneading water: pore structure and capillary porosity, Appl. Surf. Sci. (2005) (Available on line, sciencedirect.com)

[2] J. Lanas, J.I. Alvarez, Masonry repair lime-based mortars: Factors affecting the mechanical behaviour, Cem. Concr. Res., 33 (2003) 1867-1876.

[3] A. Benazzouk, O. Douzane, M. Quéneudec, Transport of fluids in cement-rubber composites, Cem. Concr. Comp., 26 (2004) 21-29.

[4] S. Kolias, C. Georgiou, The effect of paste volume and of water content on the strength and water absorption of concrete, Cem. Concr. Comp., 27 (2005) 211216.

[5] A. Stazi, M. D’Orazio, E.Quagliarini, In-life prediction of hydrometric behaviour of building materials: an application of fractal geometry to the determination of adsorption and suction properties, Build. Environ. 37 (2002) 733-739.

[6] Y.F. Houst, F.H. Wittmann, Influence of porosity and water content on the diffusivity of $\mathrm{CO}_{2}$ through hydrated cement paste, Cem. Concr. Res. 24(6) (1994) 1165-1176. 
[7] K. V. Balen, D. V.Gemert, Modelling lime mortar carbonation, Mater. Struct., 27 (1994) 393-398.

[8] N.S. Martys, C.F. Ferraris, Capillary transport in mortars and concrete, Cem. Concr. Res. 27 (5) (1997) 747-760.

[9] M.S. Goual, F. de Barquin, M.L. Benmaled, A. Bali, M. Quéneudec, Estimation of capillary transport coefficient of Clayey Aerated Concrete using a gravimetric thecnique, Cem. Concr. Res. 30 (2000) 1559-1563.

[10] A. Yan, K. Wu, D. Zhang, W Yao, Influence of concrete composition on the characterization of fracture surface, Cem. Concr. Comp. 25 (2003) 153-157.

[11] D.A. Lange, H.M. Jennings, S.P. Shah, Image analysis techniques for characterization of pore structure of cement-based materials, Cem. Concr. Res. 24(5) (1994) 841-853.

[12] UNE-EN 459-1, Building Lime: Part 1. Definition, specification and conformity criteria, 1996.

[13] UNE 80.301:1996 Cementos comunes: Composición especificaciones y criterios

[14] RILEM, Mater. Struct. 13 (1980) 175-253.

[15] O. Cazalla, C. Rodríguez-Navarro, E. Sebastián, G. Cultrone, Aging of lime putty: Effect on tradicional lime mortar carbonation, J. Am. Ceram. Soc. 83 (2000) 1070-1076.

[16] G.W. Scherer, Structure and properties of gels, Cem. Concr. Res. 29 (1999) 11491157.

[17] F.M. Lea, The chemistry of cement and concrete, Glasgow, Edward Arnold $(1970)$

[18] S. Diamond, The microstructure of cement paste and concrete - a visual primer Cem. Concr. Comp. 26 (2004) $919-933$. 
[19] S. Diamond, Mercury porosimetry, An inappropriate method for the measurement of pore size distributions in cement-based materials, Cem. Concr. Res. 30 (2000) $1517-1525$

[20] S.P. Pandey, R.L. Sharma, The influence of mineral additives on the strength and porosity of OPC mortar, Cem. Concr. Res. 30 (2000) 19-23.

[21] R. Kumar, B. Bhattacharjee, Assessment of permeation quality of concrete through mercury intrusion porosimetry, Cem. Concr. Res. 34 (2004) 321-328.

[22] S. Diamond, Aspects of concrete porosity revisited, Cem. Concr. Res. 29 (1999) $1181-1188$.

[23] Y. Wang, S. Diamond, A fractal study of the fracture surfaces of cement pastes and mortars using a stereoscopic SEM method, Cem. Concr. Res. 31 (2001) 13851392.

[24] J.L. Pérez Bernal, M.A Bello López, Fractal geometry and mercury porosimetry: Comparison and application of proposed models on building stones, Appl. Surf. Sci. 185 (2001) 99-107.

[25] B. Zhang, S Li, Determination of the surface fractal dimension for porous media by mercury porosimetry, Ind. Eng. Chem. Res. 34 (1995) 1383-1386.

[26] P. Pfeifer, M. Obert, in: D. Avnir (Ed.), The Fractal Approach to Heterogeneous Chemistry, Wiley, New York, 1989, p.16.

[27] N. Narayanan, K. Ramamurthy, Microstructural investigations on aerated concrete, Cem. Concr. Res. 30 (2000) 457- 464. 


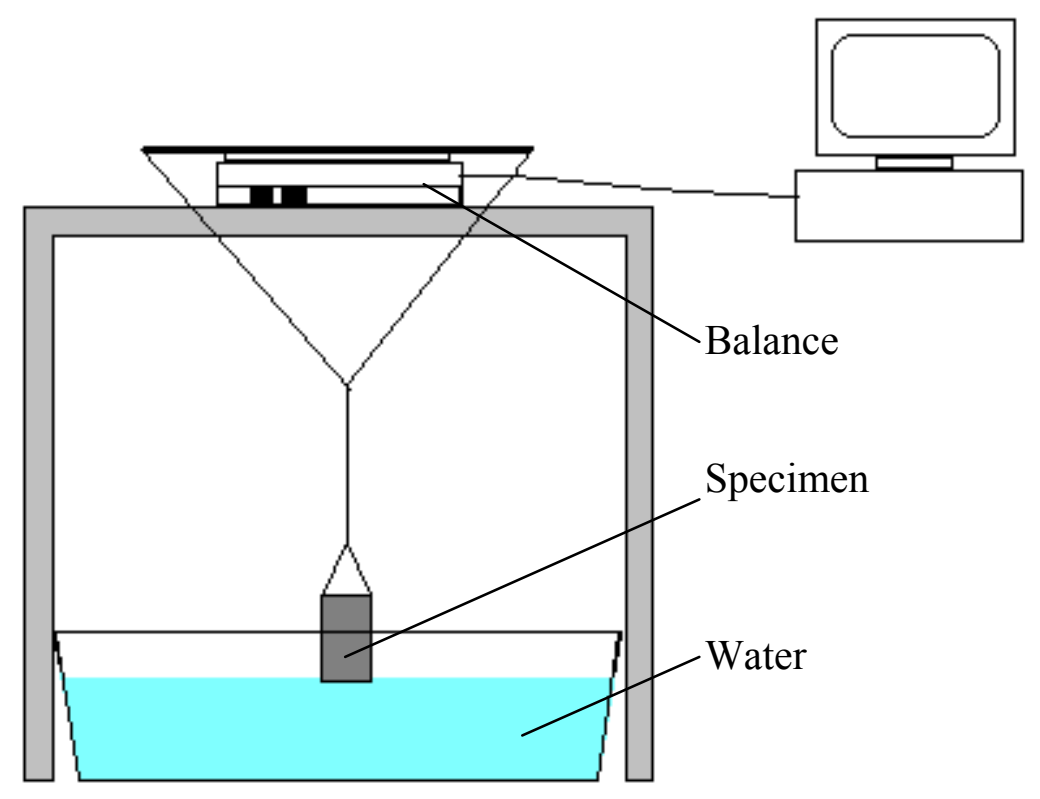

Fig. 1. Diagram of the assembly used to the capillary sorption measurements. 


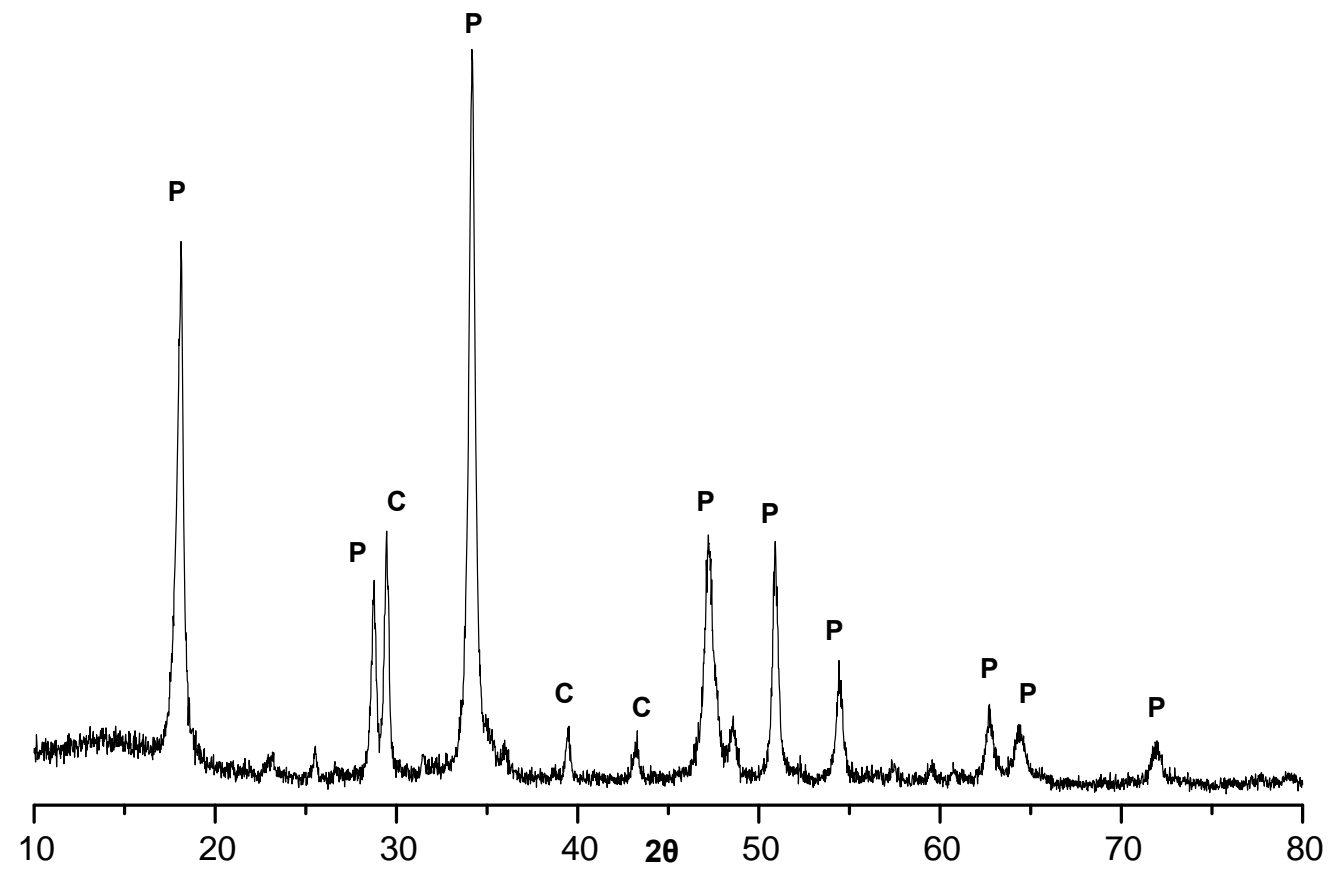

Fig. 2. XRD of the lime Ecobat ${ }^{\circledR}$ (C: Calcite (ICDD 05-0586); P: Portlandite (ICDD 441481)). 


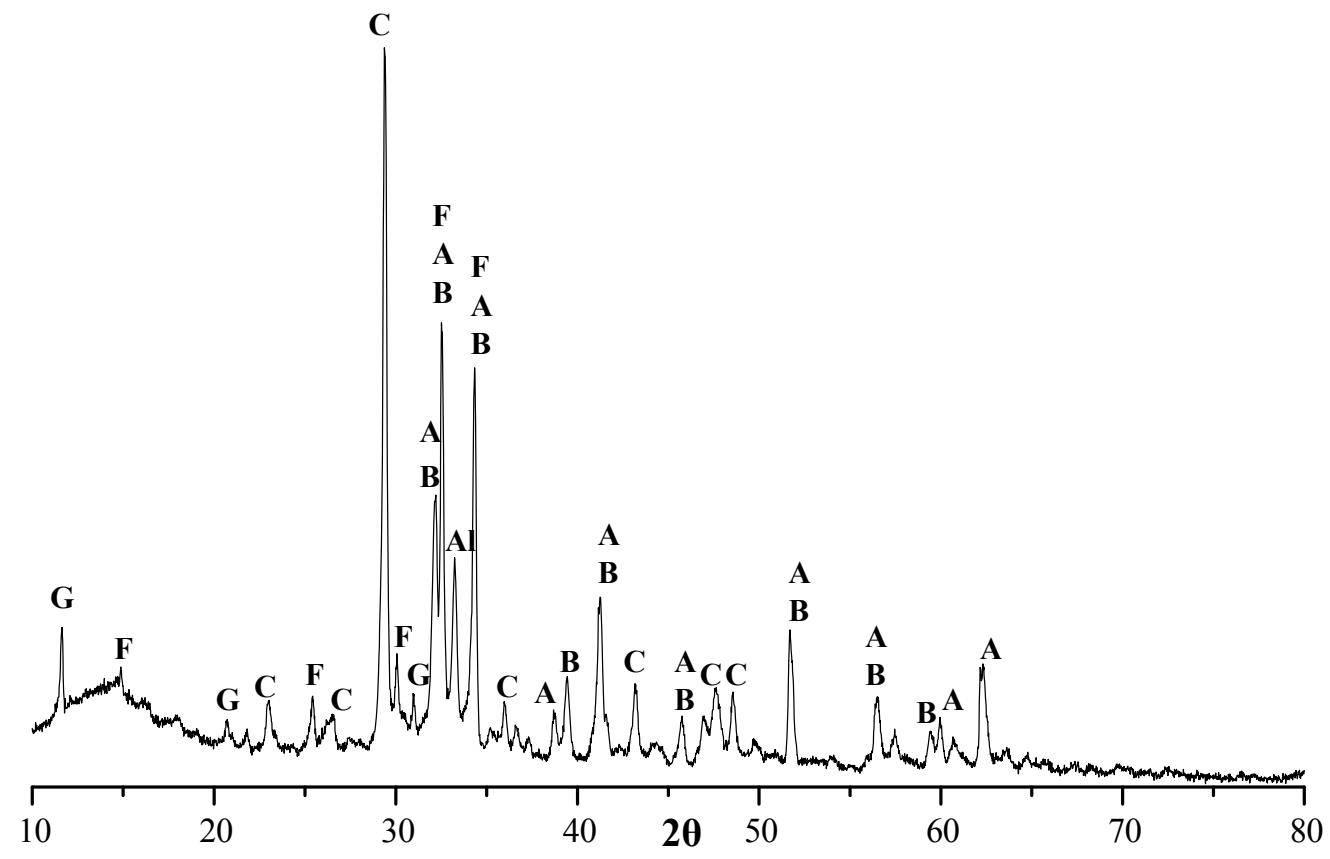

Fig. 3. XRD of the cement CEM II-A/L 32.5 (C: Calcite (ICDD 05-0586); B: Belite (ICDD 02-0843); A: Alite (ICDD 02-0849); G: Calcium sulphate hydrated (ICDD 010385); Al: Calcium aluminate (ICDD 38-1429)), F: Aluminoferrite (ICDD 85-1092). 


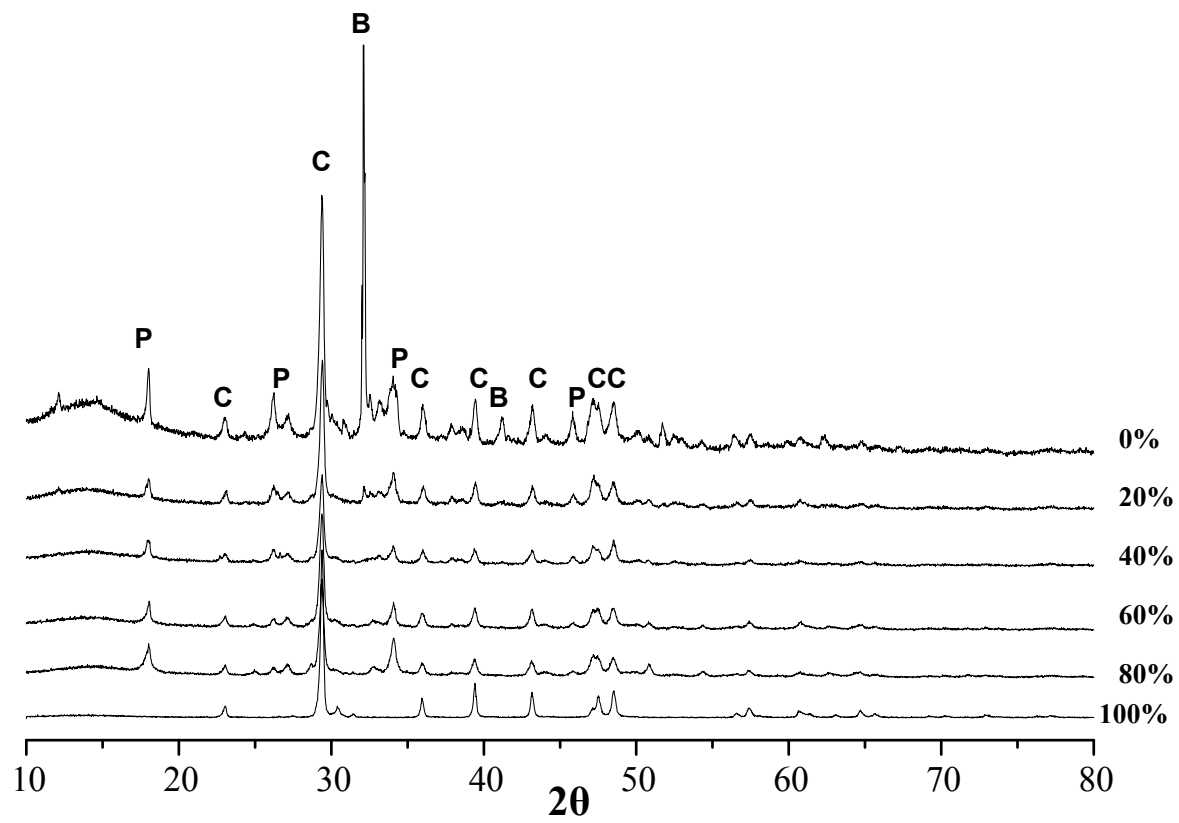

Fig. 4. XRD of the specimens after two curing years (C: Calcite (ICDD 05-0586); B: Belite (ICDD 02-0843); P: Portlandite (ICDD 44-1481)). 

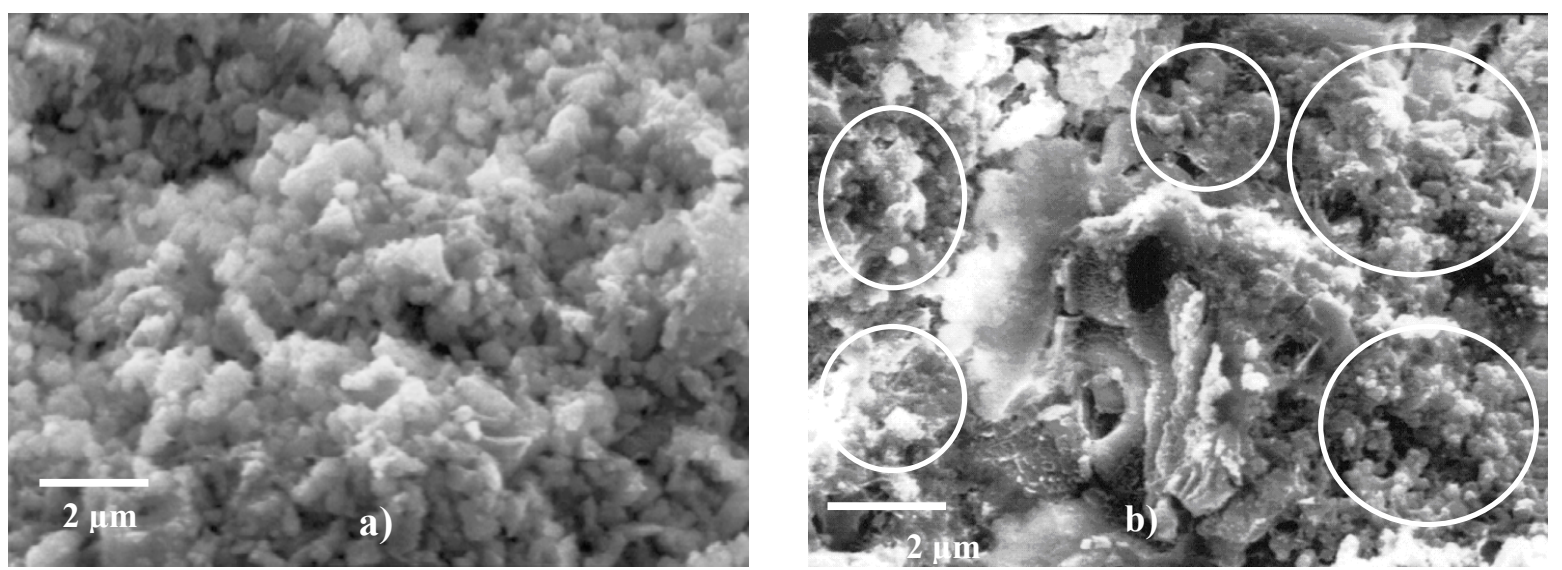

Fig. 5. SEM images of: a) lime paste; b) $40 \%$ lime $60 \%$ cement paste (the circled areas show the calcite crystals. In the center of the image, a CSH structure can be seen). 

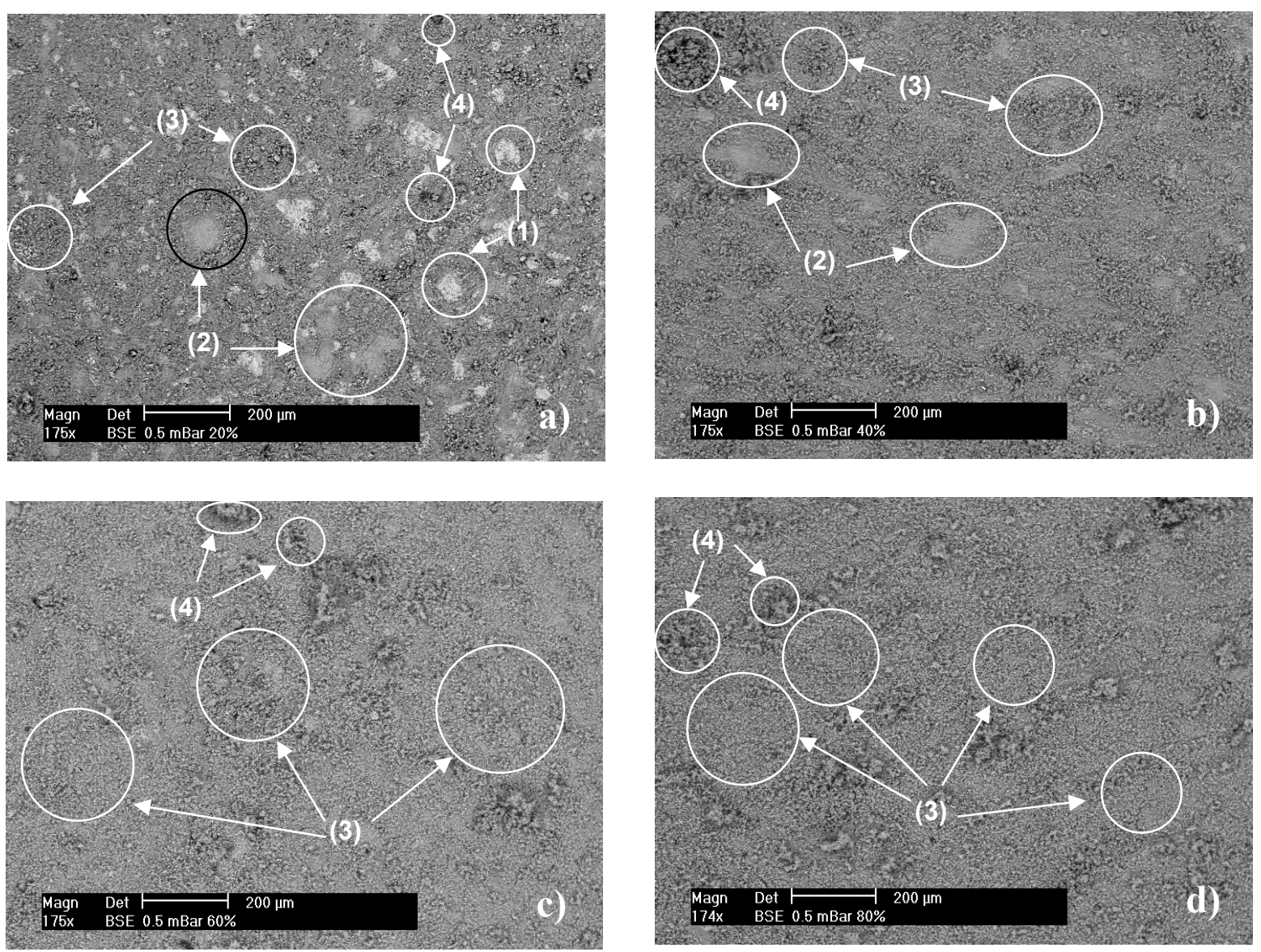

Fig. 6. BSE images with a focus of $175 x$ of blended pastes: a) $20 \%$; b) $40 \%$; c) $60 \%$; d) $80 \%$ of lime. (1) Area showing the unreacted calcium silicates; (2) area showing the full hydrated calcium silicates. The black circle shows clearly the hydration rim of CSH [18]); (3) area showing lime; (4) pores into the structure. 

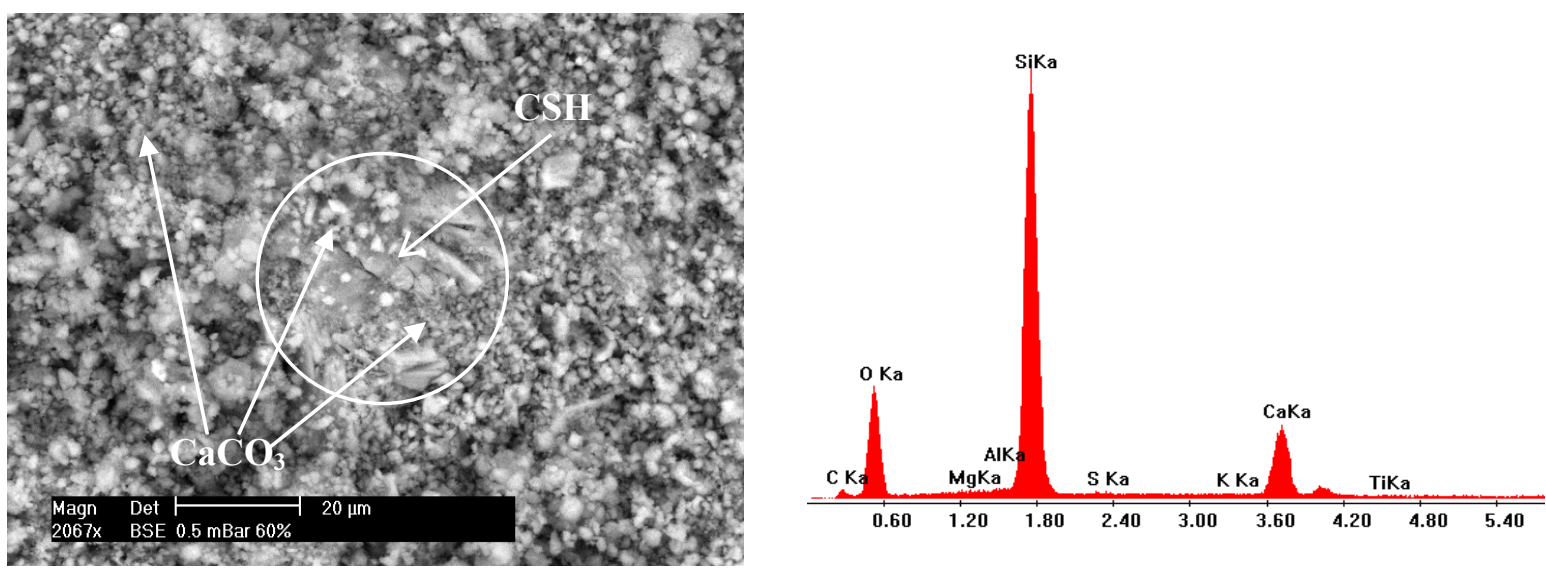

Fig. 7. BSE image and EDAX of a dense particle in the $60 \%$ lime paste. 


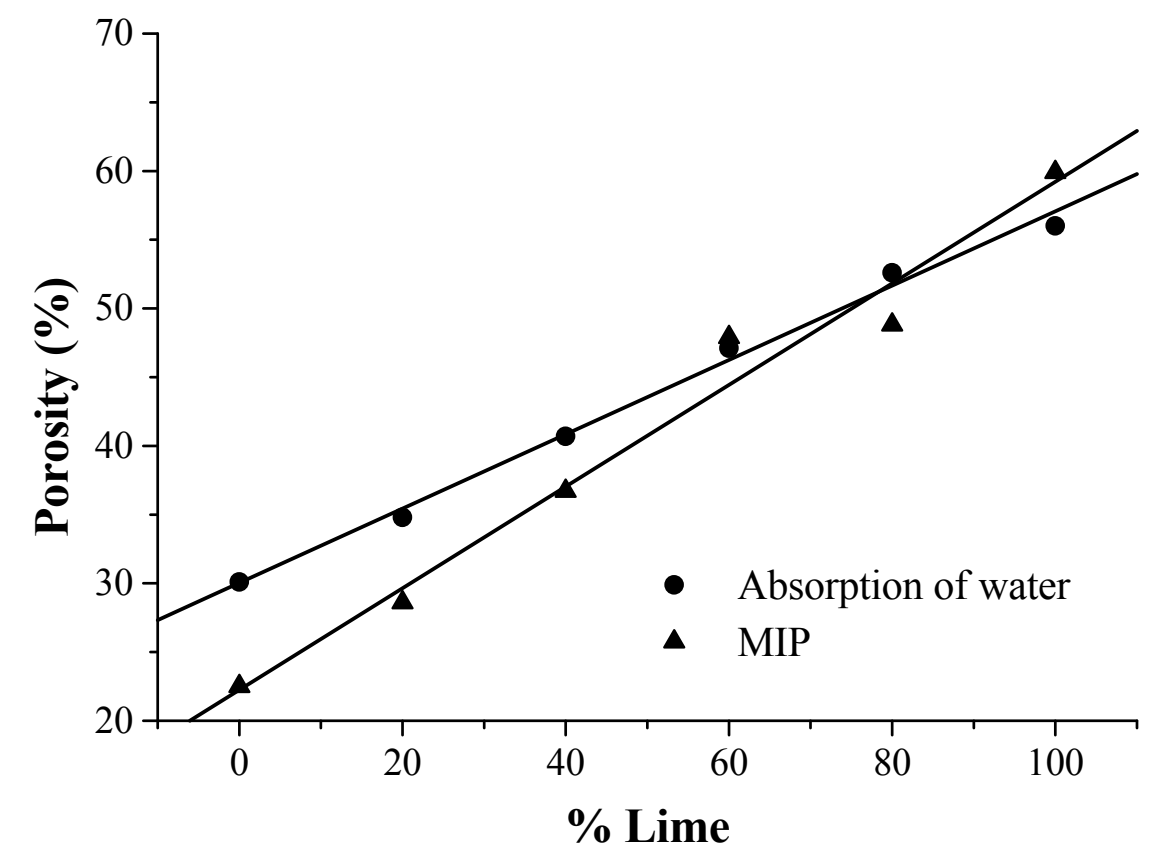

Fig. 8. Porosity obtained by MIP and absorption of water by immersion. 


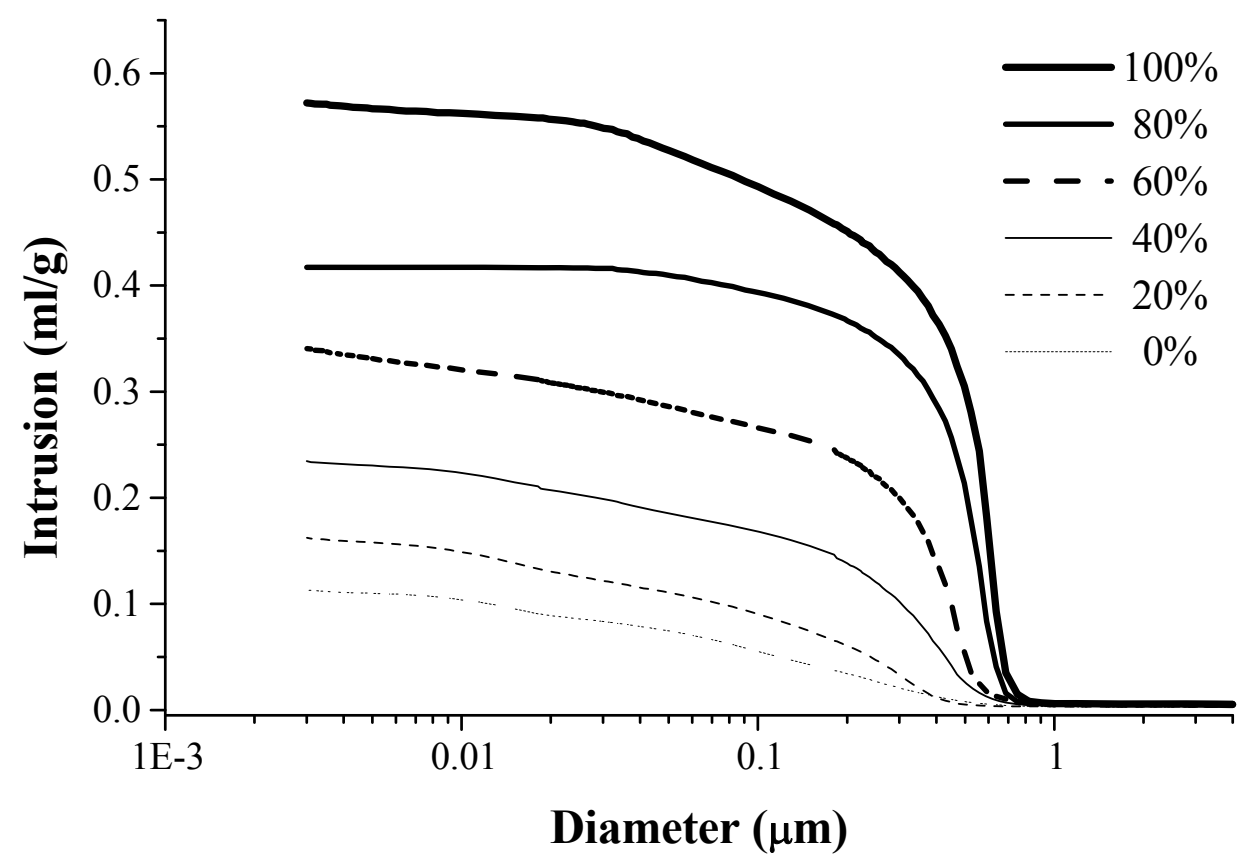

Fig. 9. Cumulative pore size distribution for the different blended pastes. 


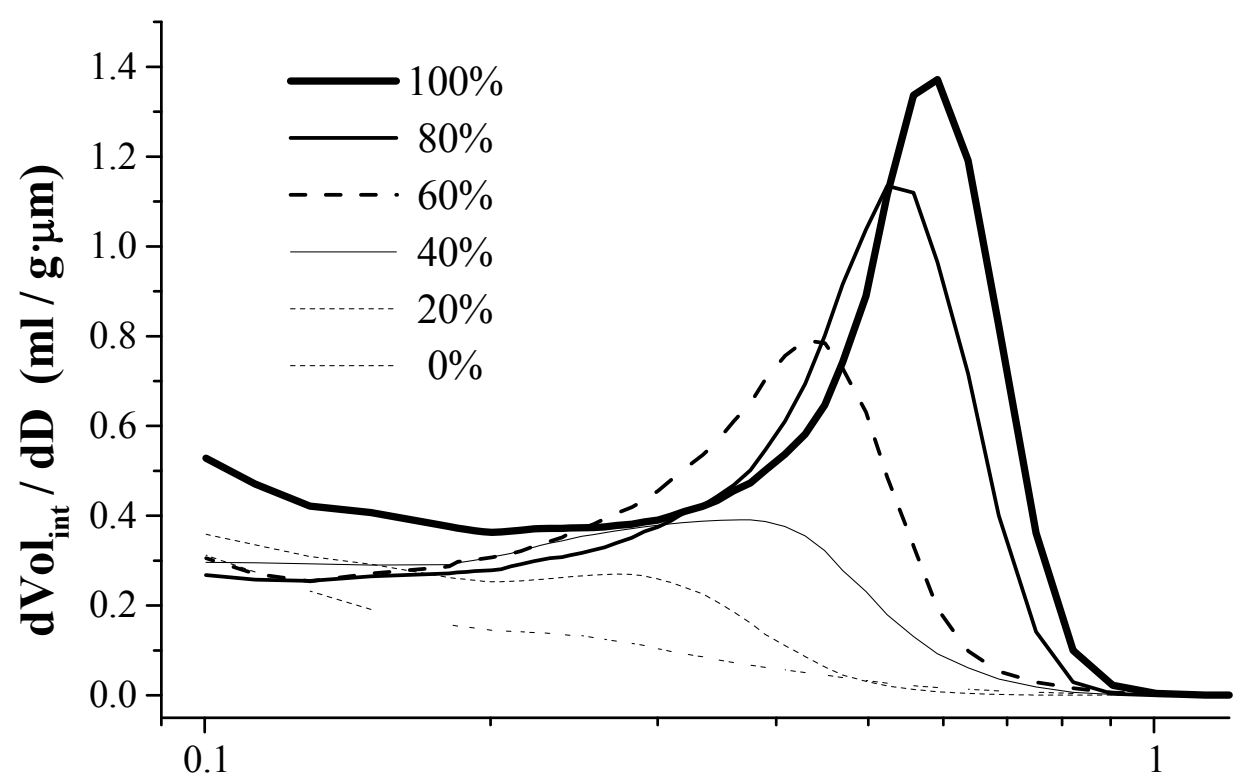

Diameter $(\mu \mathrm{m})$

Fig. 10. Derivative of the intrusion volume respect to the diameter of pore vs. the diameter of pore for the different pastes. 

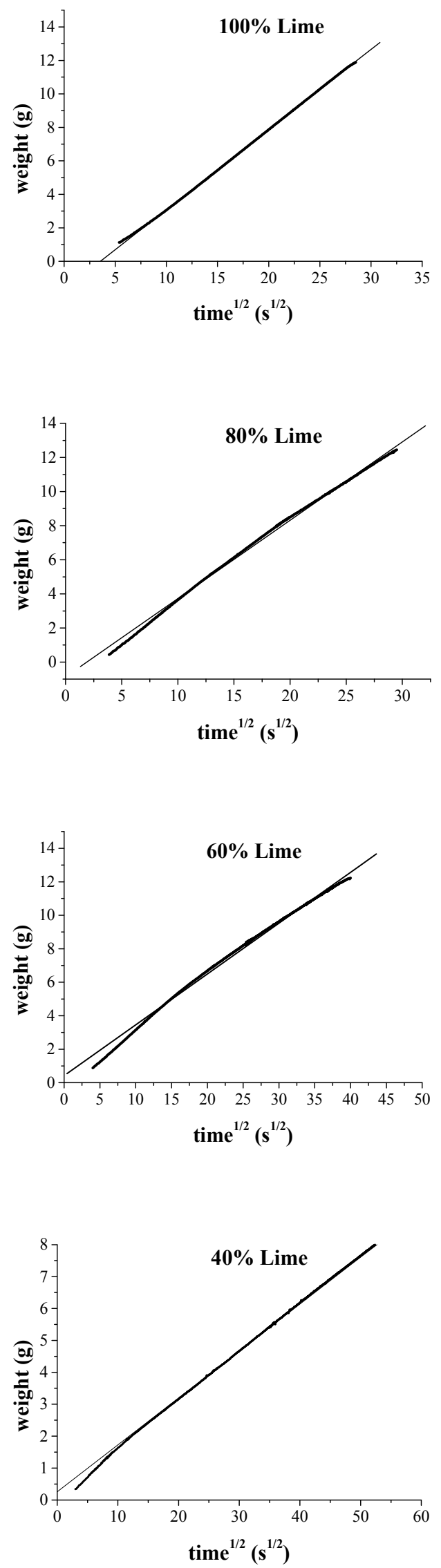

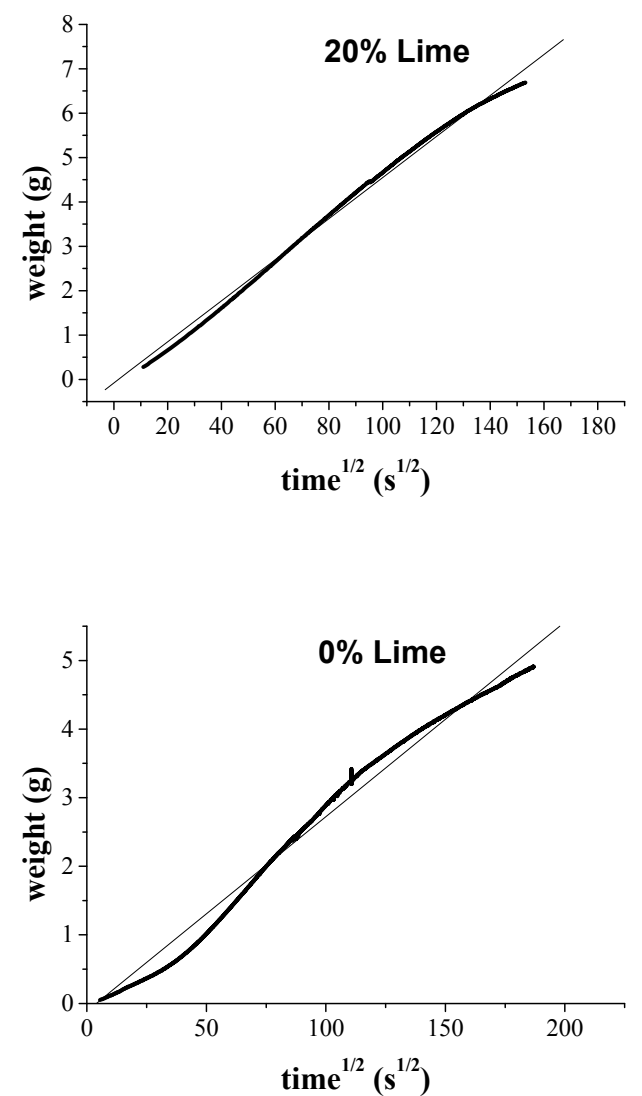

Fig. 11. Mass of adsorbed water per area vs. $t^{1 / 2}$ for the six different pastes 


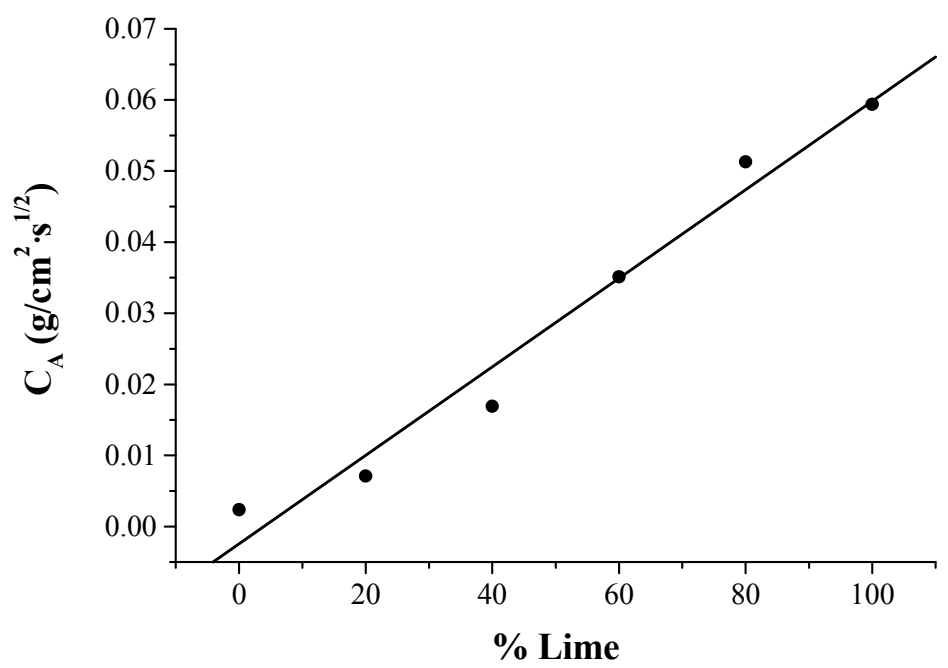

Fig. 12. Capillary coefficient $\left(\mathrm{C}_{\mathrm{A}}\right)$ vs. percentage of lime in the pastes. 
Table 1. Amount of materials blended to elaborate the pastes, and the W/B ratio.

\begin{tabular}{|c|c|c|c|c|c|c|}
\hline & $\mathbf{1 0 0} \%$ & $\mathbf{8 0 \%}$ & $\mathbf{6 0 \%}$ & $\mathbf{4 0 \%}$ & $\mathbf{2 0 \%}$ & $\mathbf{0 \%}$ \\
\hline Cement (g) & 0 & 310 & 680 & 1350 & 2080 & 3000 \\
\hline Lime (g) & 1300 & 1240 & 1020 & 900 & 520 & 0 \\
\hline Water (g) & 1180 & 1120 & 1000 & 1100 & 960 & 870 \\
\hline W/B ratio & 0.91 & 0.72 & 0.59 & 0.49 & 0.37 & 0.29 \\
\hline
\end{tabular}


Table 2. Chemical analysis of the main components of the hydrated commercial lime powder $(\text { Ecobat } \AA)^{\mathrm{a}, \mathrm{b}}$, and the Portland cement CEM II-A/L 32.5.

\begin{tabular}{|c|c|c|c|c|c|c|c|c|}
\hline & $\begin{array}{c}\mathbf{L O I}^{\mathbf{c}} \\
(\mathbf{\%})\end{array}$ & $\begin{array}{c}\mathrm{SiO}_{2} \\
\mathbf{( \% )}\end{array}$ & $\begin{array}{c}\mathbf{C a O} \\
\mathbf{( \% )}\end{array}$ & $\begin{array}{c}\mathbf{M g O} \\
(\mathbf{\%})\end{array}$ & $\begin{array}{c}\mathbf{R}_{2} \mathbf{O}_{3}{ }^{\mathbf{d}} \\
\mathbf{( \% )}\end{array}$ & $\begin{array}{c}\mathbf{S O}_{3} \\
(\mathbf{\%})\end{array}$ & $\begin{array}{c}\mathbf{N a}_{2} \mathbf{O} \\
(\mathbf{\%})\end{array}$ & $\begin{array}{c}\mathbf{K}_{2} \mathbf{O} \\
(\mathbf{\%})\end{array}$ \\
\hline Lime & 25.25 & 1.03 & 68.53 & 3.29 & 0.89 & 1.37 & 0.09 & 0.05 \\
\hline S.D.* & 1.20 & 0.10 & 1.10 & 0.42 & 0.11 & 0.22 & 0.02 & 0.03 \\
\hline Cement & 6.94 & 16.23 & 58.28 & 4.65 & 9.99 & 2.35 & 0.38 & 0.35 \\
\hline S.D. ${ }^{*}$ & 0.90 & 0.23 & 0.84 & 0.35 & 1.12 & 0.27 & 0.04 & 0.08 \\
\hline
\end{tabular}

* Standard Deviation

${ }^{\text {a }}$ Percentages related to original dry lime.

${ }^{\mathrm{b}}$ The methods specified by the European Standard EN-196 were followed for the chemical analyses.

${ }^{\mathrm{c}}$ Loss of ignition, the weight loss due to calcinations at $975-1000^{\circ} \mathrm{C}$

${ }^{\mathrm{d}}$ Percentage of $\mathrm{Fe}$ and $\mathrm{Al}$ oxides together. 
Table 3. Surface fractal dimension $\left(D_{S}\right)$ for the six pastes, obtained by MIP data.

\begin{tabular}{|c|c|c|c|c|c|c|}
\hline \% of Lime & $\mathbf{1 0 0}$ & $\mathbf{8 0}$ & $\mathbf{6 0}$ & $\mathbf{4 0}$ & $\mathbf{2 0}$ & $\mathbf{0}$ \\
\hline $\begin{array}{c}\mathbf{D}_{\mathbf{S}} \\
\text { (MIP) }\end{array}$ & 2.381 & 2.378 & 2.423 & 2.513 & 2.616 & 2.666 \\
\hline S.D.* & 0.009 & 0.013 & 0.020 & 0.022 & 0.020 & 0.019 \\
\hline
\end{tabular}

* Standard Deviation 